\title{
Treatment options for recurrence of hepatocellular carcinoma after surgical resection: review of the literature and current recommendations for management
}

\author{
Francesco Pasini ${ }^{1}$, Matteo Serenari ${ }^{1}$, Alessandro Cucchetti ${ }^{1,2}$, Giorgio Ercolani ${ }^{1,2}$ \\ 'Department of Medical and Surgical Sciences, University of Bologna, Bologna 40138, Italy. \\ Department of Surgery, "Morgagni - Pierantoni" Hospital, Forli 47121, Italy.
}

Correspondence to: Giorgio Ercolani, Department of Medical and Surgical Sciences - DIMEC, University of Bologna; Via Massarenti 9, Bologna 40138, Italy. E-mail: giorgio.ercolani2@unibo.it

\begin{abstract}
How to cite this article: Pasini F, Serenari M, Cucchetti A, Ercolani G. Treatment options for recurrence of hepatocellular carcinoma after surgical resection: review of the literature and current recommendations for management. Hepatoma Res 2020;6:26. http://dx.doi.org/10.20517/2394-5079.2019.47
\end{abstract}

Received: 21 Dec 2019 First Decision: 9 Mar 2020 Revised: 23 Mar 2020 Accepted: 2 Apr 2020 Published: 16 May 2020

Science Editor: Stefano Brillanti Copy Editor: Jing-Wen Zhang Production Editor: Jing Yu

\begin{abstract}
The recurrence rate after primary resection for hepatocellular carcinoma (HCC) has been reported to be up to $80 \%$. There is no consensus or guideline about the best treatment option for such recurrent HCC (rHCC). It is therefore of paramount importance to select patients for suitable treatment due to the high risk of associated morbidity and mortality. In this paper, we review the literature on treatment for $\mathrm{rHCC}$ and propose a strategy based on the best evidence available. Even in $\mathrm{rHCC}$, it is still possible to achieve cure and good survival rates through careful patient selection. Repeat hepatectomy is recognized as a feasible and safe procedure even in cirrhotic patients and should be considered as the best option with curative intent when the patient is fit enough. Greater adoption of minimally-invasive liver surgery could have the potential to increase the number of candidate patients with $\mathrm{rHCC}$ for repeat resection in the next few years. Liver transplantation offers longer disease-free survival compared to repeat resection, curing the underlying cirrhosis, but is not widely available due to organ shortage. When surgery is not feasible, locoregional treatments such as radiofrequency ablation and transarterial chemoembolization have an important role for patients who cannot tolerate repeat hepatectomy and are not suitable for transplantation. For advanced cases, systemic therapy could be considered.
\end{abstract}

Keywords: Recurrence, hepatocellular carcinoma, hepatic resection, second resection

\footnotetext{
(@) (

(C) The Author(s) 2020. Open Access This article is licensed under a Creative Commons Attribution 4.0 International License (https://creativecommons.org/licenses/by/4.0/), which permits unrestricted use, sharing, adaptation, distribution and reproduction in any medium or format, for any purpose, even commercially, as long as you give appropriate credit to the original author(s) and the source, provide a link to the Creative Commons license, and indicate if changes were made.
}

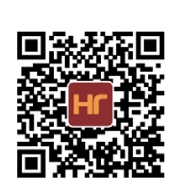




\section{INTRODUCTION}

Hepatocellular carcinoma (HCC) is the third most common cause of cancer related death worldwide ${ }^{[1]}$ and its incidence in Western countries has increased by $75 \%$ in the last three decades ${ }^{[2]}$. Liver resection represents first-line treatment in patients with early tumors and preserved liver function, with a 5-year overall survival ranging from $60 \%$ to $80 \%$. Nonetheless, HCC frequently arises from chronic liver disease and the recurrence rate in the remnant liver, even after Ro resection, has been reported to be up to $80 \%{ }^{[3]}$. Although guidelines from European, American and Eastern societies recommend hepatic resection as first-line treatment with curative intent for primary $\mathrm{HCC}^{[3-5]}$, none exist for recurrent liver cancers. Liver transplantation, in the case of recurrent HCC (rHCC), would offer the best chance at disease-free survival, by treating both the cancer and the underlying cirrhosis at the same time, but the scarcity of deceased organs limits its application. Furthermore, surgical treatment may not always be feasible and non-surgical options should then be considered.

To date, many papers have been published on the treatment algorithm for rHCC but evidence and consensus are still lacking. These studies are mainly from Eastern centers and almost all are retrospective data.

In this paper, we reviewed the literature on treatment for rHCC and propose our personal strategy based on the available evidence.

\section{TREATMENT OPTIONS FOR RECURRENT HCC}

\section{Repeat hepatectomy}

Liver resection is recognized as the mainstay of treatment in patients with HCC. In both Eastern and Western countries ${ }^{[6]}$, it is the first choice option in non-cirrhotic patients who can tolerate resections with low morbidity and mortality ${ }^{[7,8]}$. On the other hand, HCC resection in cirrhotic livers requires careful patient selection and adequate surgical skills. Patient selection relies mainly on the preoperative assessment of reserve liver function and portal hypertension. Traditionally, liver function is evaluated through standard liver biochemical tests integrated into several scores such as the Child-Pugh or MELD score ${ }^{[9]}$, but nowadays, more sophisticated quantitative liver function tests such as indocyanine green retention (ICG) test ${ }^{[10,1]}$ or hepatobiliary scintigraphy ${ }^{[12,13]}$, are used in predicting post-hepatectomy liver failure. The presence of clinically relevant portal hypertension can be ruled out by measuring the hepatic vein pressure gradient, or indirectly by liver stiffness, to decrease the risk of postoperative decompensation ${ }^{[14-16]}$.

According to the BCLC algorithm, patients with a single, very early- or early-stage HCC and preserved liver function should be offered liver resection ${ }^{[4]}$. While international guidelines tend to reserve resection for patients harboring early stage HCC, expert institutions have shown good outcomes even in patients with multinodular, large, and macrovascular, invasive $\mathrm{HCC}^{[17]}$, thus justifying expansion of HCC resectability criteria. However, even after potentially curative resections with negative margins, early recurrence accounts for more than $70 \%$ of rHCC and occurs within 2 years in $30 \%-50 \%$ of patients. The recurrence rate at 5 years has been reported to range from $50 \%$ to $70 \%{ }^{[18-20]}$. The key parameters related to recurrence include tumour size, multinodular tumours, serum alpha-fetoprotein and microvascular invasion ${ }^{[21]}$.

Currently, there are no guidelines or clinical algorithms for the best treatment option in $\mathrm{rHCC}^{[22,23]}$ except for expert opinion and local policies. Many authors agree with re-resection as the best therapeutic option for rHCC, when feasible. Improvement in surgical technique and implementation of the use of energy devices have led to a lower incidence of complications. Liver resections are therefore safer in patients with previous resection. Concern still exists however and is mainly related to poor remnant liver function and adhesions caused by previous surgery that could lead to iatrogenic injuries. Many studies have addressed 
this topic, showing that repeat hepatectomy $(\mathrm{RH})$ can be performed safely with complication rates comparable to the first resection ${ }^{[2]}$. Another issue is the risk of further recurrence, which is dependent on the presence of multinodular cirrhosis in the remnant liver ${ }^{[25,26]}$.

Most case series of rHCC treated with RH are from Eastern Asia. Since none were randomized trials and patients were selected for resection according to different clinical criteria and hospital policies, comparison is difficult. Nagasue et al. ${ }^{[27]}$ first reported a small series of RH carried out in 9 of 31 patients who experienced tumor recurrence after initial resection of primary HCC. They reported that the survival rate of resected patients was significantly better than that of patients treated with palliative methods. $\mathrm{Hu}$ et al ${ }^{[28]}$ described a retrospective analysis of 59 patients who were treated with RH. 43 had a second recurrence (median follow up 19 months) and survival at three years was 44\%. Another paper from the same institution ${ }^{[2]]}$ compared RH to TACE for rHCC and advocated for aggressive surgical treatment after recurrence in selected patients.

Larger series have since been published in the last 20 years, again mainly from Eastern institutions, with 5-year overall survival (OS) ranging from $30 \%$ to $60 \%{ }^{[30-33]}$. In 2011 , Roayaie et al ${ }^{[34]}$ presented the first and largest Western series of RH $(n=35)$, showing an overall 5 -year survival rate of $67 \%$. Only patients with a single recurrent tumor on imaging, Child's A liver disease and a platelet count $>100,000 / 11$ underwent RH.

Several studies have been published in recent years and have established RH as safe in referral centers [Table 1]. The largest Eastern series by Zou et al. ${ }^{[35]}$ reported 635 consecutive patients who received a second resection for rHCC. The median OS was 54.8 months and the 1-, 3-, and 5-year OS rates were 96.9\%, $74.8 \%$, and $47.8 \%$, respectively. Post-recurrence survival (i.e., calculated from the date of reoperation) rates were $75.8 \%, 45.7 \%$ and $37.6 \%$, respectively. In this large, single institution series, a perioperative complication rate of $22.8 \%$ was reported with a median blood loss of $303 \mathrm{~mL}$ (range 100-5300). With regard to postoperative complications, a systematic review by Chan et al. ${ }^{[36]}$ reported a median mortality rate of $0 \%$ (ranging from $0 \%$ to $6 \%$ ) and a postoperative bleeding rate (with need for transfusions) of $1 \%$. Other postoperative complications (ascites, bile leak, liver failure) were in line with those reported in the literature for patients without preoperative liver surgery.

\section{ROLE OF MINIMALLY-INVASIVE SURGERY}

The adoption of laparoscopic liver resection (LLR) has increased over the past decade. Laparoscopy for HCC has been shown in studies to produce superior short-term and equivalent long-term outcomes compared to the open approach. However, due to the formation of intra-abdominal adhesions, LLR for rHCC after previous hepatic resection may represent a challenge. For this reason, there are only a few studies reporting a laparoscopic approach to treat liver recurrence. However, this number is believed to rise in the next few years since liver resection will increasingly be approached laparoscopically. A recent meta-analysis showed that LLR for rHCC offered a benefit in terms of lower in-hospital complication rates, blood loss and a shorter hospital stay compared to open resection, although similar 90-day mortality was observed between the two groups ${ }^{[45]}$. This could be partially explained by the fact that, unlike conventional laparotomy, the laparoscopic approach does not require a wide surgical field, thus minimizing the freeing of adhesions and consequently, bleeding as well as other intraoperative complications. Even the scoring system for predicting complications in LLR proposed by Halls et al. ${ }^{[46]}$ showed that a previous open liver resection was the strongest among all independent risk factors $(\beta$ coefficient $=1.401)$ of having high blood loss or conversion to an open approach during surgery. This finding should prompt us to at least consider more patients for minimally-invasive surgery at the time of primary resection so as to increase the number of eligible patients who may benefit from a RH in the event of of rHCC. LLR has been also demonstrated to facilitate liver transplantation (LT) in terms of decreasing blood loss and transfusion requirements. 
Table 1. Review of the literature on the surgical treatment of recurrent hepatocellular carcinoma

\begin{tabular}{|c|c|c|c|c|}
\hline Ref. & Year & No of pts & Mortality (\%) & 5-year OS (\%) \\
\hline Zou et al. ${ }^{[35]}$ & 2016 & 635 & 7 & 47 \\
\hline Huang et $a l^{[37]}$ & 2012 & 85 & 1 & 22 \\
\hline Faber et al. ${ }^{[38]}$ & 2011 & 27 & 0 & 42 \\
\hline Roayaie et al. ${ }^{[34]}$ & 2011 & 35 & 0 & 67 \\
\hline Kubo et al..$^{[39]}$ & 2008 & 51 & 0 & 48 \\
\hline Itamoto et al. ${ }^{[40]}$ & 2007 & 84 & 0 & 50 \\
\hline Tralhão et al..$^{[41]}$ & 2007 & 16 & 1 & 31 \\
\hline Kobayashi et al. ${ }^{[42]}$ & 2006 & 80 & 0 & 53 \\
\hline Sun et $a l_{.}^{[31]}$ & 2005 & 57 & 0 & 31 \\
\hline Minagawa et al. ${ }^{[33]}$ & 2003 & 67 & 0 & 56 \\
\hline Sugimachi et al. ${ }^{[43]}$ & 2001 & 78 & 0 & 48 \\
\hline Shimada et $a l_{.}^{[30]}$ & 1998 & 41 & NR & $45(3-y)$ \\
\hline Hu et al..$^{[44]}$ & 1996 & 59 & 0 & $44(3-y)$ \\
\hline
\end{tabular}

OS: overall survival

Nevertheless, we acknowledge that this important aspect surely requires further dedicated study and every effort should be made to minimize blood loss and the associated transfusion requirements to improve outcomes in both liver surgery and LT.

\section{Liver transplantation (salvage)}

Many transplant centres recommend LT as salvage for rHCC. Salvage LT (SLT) was proposed as an ideal treatment for patients fulfilling the Milan criteria, treating both the cancer and the underlying cirrhosis at the same time $\mathrm{e}^{[47]}$. However, many authors have questioned whether RH could be performed instead of LT. A recent meta-analysis ${ }^{[48]}$ comparing SLT with RH showed that SLT was inferior to RH with regard to operative and postoperative short-term results, but had better results in terms of overall- and diseasefree survival. In fact, in SLT, a more complex operation has to be accounted for, especially in patients who are thought to have more advanced liver cirrhosis. A recent study by Lim et al. ${ }^{[49]}$ showed, in particular, that 90-day mortality was significantly higher in the SLT group compared to the RH group. The negative impact of resection on subsequent LT was also demonstrated in other studies comparing SLT and primary liver transplantation (PLT). Adam et al. ${ }^{[50]}$ first showed that LT after prior liver resection was associated with higher operative mortality and risk of intraoperative bleeding than PLT. Similarly, a recent metaanalysis has demonstrated a significantly higher rate of postoperative bleeding and operative mortality in the SLT group. However, despite the higher perioperative risk, SLT may still achieve better diseasefree survival (DFS) rates compared to RH. This has to be expected, given that resection of existing distant micrometastases and removal of the underlying liver disease may prevent de novo HCC development in the remnant liver. A recent meta-analysis ${ }^{[51]}$ comparing SLT to curative locoregional treatments among seven retrospective studies showed better outcomes with SLT. In particular, SLT was associated with higher 5-year OS and DFS; when compared to RH alone, subgroup analysis still indicated a significantly higher 3and 5-year DFS for the SLT group. Nevertheless, the authors stated that the feasibility of SLT is impaired due to donor organ shortage.

The decision to proceed with either strategy is clearly biased by institutional practices and for this reason, any comparison between SLT and RH may not be completely reliable. However, it is our opinion that patients should be listed for LT in case of worsening liver function, or any other case such that a second liver resection will not be tolerated. When feasible, any attempt to rescue these patients without affecting the donor pool should be made ${ }^{[52]}$.

\section{Locoregional treatments}

Radiofrequency ablation (RFA), applicable both via the percutaneous or open approach, is considered a safe procedure and as effective in achieving long-term survival as surgical resection, in selected patients ${ }^{[53]}$. 
In particular, RFA is proposed for small primary HCC up to $3 \mathrm{~cm}$ in diameter ${ }^{[5,55]}$. However, some authors have also proposed RFA for rHCC because of its low morbidity compared to surgical treatments, negligible blood loss and sparing of adjacent normal liver parenchyma ${ }^{[56]}$. Furthermore, in patients not amenable to surgical resection due to liver dysfunction, multifocal nodules, tumour location or postsurgical adhesions, RFA represents a potentially curative alternative. In a recent metanalysis, Gavriilidis et al. ${ }^{[57]}$ demonstrated similar 5-year OS and DFS between RFA and RH in treating rHCC although a significant difference in morbidity was reported ( $2 \%$ for RFA vs. $17 \%$ for RH). However, a systematic review of 18 previous studies published by Thomasset et al ${ }^{[58]}$ concluded that RFA for rHCC had a very low rate of complications but was still less efficacious than RH and thus, should be offered only to patients who cannot tolerate surgical resection.

A further treatment option for rHCC is trans-arterial chemoembolization (TACE), although it is not applied with curative intent ${ }^{[26,59]}$. A median survival of 30 months and a 3 -year survival of $29 \%$ has been reported in the treatment of primary HCC with TACE ${ }^{[60,61]}$; outcomes reported for $\mathrm{HHCC}$ are arguably poorer $^{[26]}$. This interventional radiology procedure should be offered to patients who are not candidates for surgical resection, SLT or RFA. Although a recent study reported TACE to be superior to RH and RFA in cases of microvascular involvement ${ }^{[62]}$, the majority of the literature consider TACE to be palliative ${ }^{[63]}$ so it is widely used as a treatment for tumours with greater sizes or number of nodules which cannot be treated with RH or RFA. A review from Erridge et al. ${ }^{[64]}$ reported a 5 year survival of $15.5 \%$ in patients with rHCC treated with TACE.

\section{Systemic therapies}

When recurrence presents beyond the limits of transplantation criteria and is not amenable to locoregional treatment, survival rates are dismal but systemic therapies can still be considered in selected cases. Effective systemic treatment for HCC have been available only in recent years - since sorafenib was introduced, it has become the standard of treatment for advanced $\mathrm{HCC}^{[4,65]}$. Several compounds have since been tested in this setting but few have proven to be effective: regorafenib was approved as a second-line treatment for patients with HCC disease progression on sorafenib ${ }^{[6]}$ and levatinib recently showed non-inferiority as first-line therapy ${ }^{[67]}$. Since good cardiovascular status and preserved liver function are both necessary for chemotherapy to be tolerated, most reports are on the use of sorafenib in patients with rHCC after $\mathrm{LT}^{[67]}$, given the poor results obtained in the adjuvant setting after resection ${ }^{[68]}$. On the contrary, when no clinical benefit is expected from chemotherapy, the management of end-stage rHCC is symptomatic and only supportive care should be offered ${ }^{[68]}$.

\section{SUMMARY}

Herein, we propose our recommendations for selecting the best candidate, and limiting the risk of rerecurrence in cases of $\mathrm{rHCC}$, based on the above literature review, available guidelines on primary HCC and our personal experiences.

\section{RH}

Patients presenting with a single rHCC should undergo repeat resection whenever possible. Candidates for $\mathrm{RH}$ are required to have preserved liver function and no or limited signs of portal hypertension. The laparoscopic approach should be considered for $\mathrm{RH}$ in $\mathrm{rHCC}$ when the requisite expertise is available.

\section{RFA}

Patients with preserved liver function and a single $\mathrm{rHCC} \leq 3 \mathrm{~cm}$ can be considered for RFA. RFA should be preferred over RH, especially in cases of patients with high surgical risk. 


\section{TACE}

Patients with deteriorated liver function can be treated with TACE. Patients planned for LT should also be considered for TACE as bridging.

\section{SLT}

Patients with decompensated liver function, severe portal hypertension and single or even multiple liver recurrences, but still fulfilling LT criteria, may be referred for SLT.

\section{Systemic therapies}

In the setting of rHCC not amenable to other treatments due to disease that is far too advanced, systemic therapies can be employed in selected cases.

\section{CONCLUSION}

Recurrent HCC may occur after liver resection in up to $80 \%$ of cases. A standardized treatment algorithm for rHCC does not exist but surgical resection should be attempted whenever possible, since it may provide favourable long-term outcomes with acceptable perioperative risk comparable to primary resection. In experienced hands, laparoscopic liver resection for both primary and recurrent HCC should be considered. LT should be considered in all cases where surgical resection cannot be performed, especially in the context of underlying cirrhosis, if conventional transplantation criteria are met. The use of RFA or TACE as a bridge to LT, or for palliation represent alternatives for these patients.

\section{DECLARATIONS}

\section{Authors' contributions}

Made substantial contributions to conception of the paper, reviewed the literature and drafted the manuscript; equally contributed to the work: Pasini F, Serenari M

Supervised the work, reviewed the manuscript, provided technical support and expert guidance: Cucchetti A, Ercolani G

\section{Availability of data and materials}

Not applicable.

\section{Financial support and sponsorship}

None.

\section{Conflicts of interest}

All authors declared that there are no conflicts of interest.

\section{Ethical approval and consent to participate}

Not applicable.

\section{Consent for publication}

Not applicable.

\section{Copyright}

(c) The Author(s) 2020.

\section{REFERENCES}

1. Bray F, Ferlay J, Soerjomataram I, Siegel RL, Torre LA, et al. Global cancer statistics 2018: GLOBOCAN estimates of incidence and mortality worldwide for 36 cancers in 185 countries. CA Cancer J Clin 2018;68:394-424. 
2. Akinyemiju T, Abera S, Ahmed M, Alam N, Alemayohu MA, et al.; Global Burden of Disease Liver Cancer Collaboration. The burden of primary liver cancer and underlying etiologies from 1990 to 2015 at the global, regional, and national level results from the global burden of disease study 2015. JAMA Oncol 2017;3:1683-91.

3. Kokudo N, Takemura N, Hasegawa K, Takayama T, Kubo S, et al. Clinical practice guidelines for hepatocellular carcinoma: the Japan Society of Hepatology 2017 (4th JSH-HCC guidelines) 2019 update. Hepatol Res 2019;49:1109-13.

4. European Association for the Study of the Liver. EASL Clinical Practice Guidelines: Management of hepatocellular carcinoma. J Hepatol 2018;69:182-236.

5. Bruix J, Sherman M; American Association for the Study of Liver Diseases. Management of hepatocellular carcinoma: an update. Hepatology 2011;53:1020-2.

6. Bralet MP, Régimbeau JM, Pineau P, Dubois S, Loas G, et al. Hepatocellular carcinoma occurring in nonfibrotic liver: epidemiologic and histopathologic analysis of 80 French cases. Hepatology 2000;32:200-4.

7. El-Serag HB. Hepatocellular carcinoma. N Engl J Med 2011;365:1118-27.

8. Llovet JM, Fuster J, Bruix J. Intention-to-treat analysis of surgical treatment for early hepatocellular carcinoma: resection versus transplantation. Hepatology 1999;30:1434-40.

9. Cucchetti A, Ercolani G, Vivarelli M, Cescon M, Ravaioli M, et al. Impact of model for end-stage liver disease (MELD) score on prognosis after hepatectomy for hepatocellular carcinoma on cirrhosis. Liver Transpl 2006;12:966-71.

10. Miyagawa S, Makuuchi M, Kawasaki S, Kakazu T. Criteria for safe hepatic resection. Am J Surg 1995;169:589-94.

11. Seyama Y, Kokudo N. Assessment of liver function for safe hepatic resection. Hepatol Res 2009;39:107-16.

12. Serenari M, Collaud C, Alvarez FA, de Santibañes M, Giunta D, et al. Interstage assessment of remnant liver function in alpps using hepatobiliary scintigraphy: prediction of posthepatectomy liver failure and introduction of the HIBA index. Ann Surg 2018;267:1141-7.

13. Serenari M, Pettinato C, Bonatti C, Zanoni L, Odaldi F, et al. Hepatobiliary scintigraphy in the preoperative evaluation of potential living liver donors. Transplant Proc 2019;51:167-70.

14. Cucchetti A, Cescon M, Golfieri R, Piscaglia F, Renzulli M, et al. Hepatic venous pressure gradient in the preoperative assessment of patients with resectable hepatocellular carcinoma. J Hepatol 2016;64:79-86.

15. Qi X, Zhang X, Li Z, Hui J, Xiang Y, et al. HVPG signature: A prognostic and predictive tool in hepatocellular carcinoma. Oncotarget 2016;7:62789-96.

16. Cescon M, Colecchia A, Cucchetti A, Peri E, Montrone L, et al. Value of transient elastography measured with FibroScan in predicting the outcome of hepatic resection for hepatocellular carcinoma. Ann Surg 2012;256:706-12.

17. Torzilli G, Belghiti J, Kokudo N, Takayama T, Capussotti L, et al. Reply to Letter: "A snapshot of the effective indications and results of surgery for hepatocellular carcinoma in tertiary referral centers: is it adherent to the EASL/AASLD recommendations? An observational Study of the HCC East-West Study Group": when the study setting "ignores" the patients. Ann Surg 2015;262:e30-1.

18. Imamura H, Matsuyama $\mathrm{Y}$, Tanaka $\mathrm{E}$, Ohkubo T, Hasegawa $\mathrm{K}$, et al. Risk factors contributing to early and late phase intrahepatic recurrence of hepatocellular carcinoma after hepatectomy. J Hepatol 2003;38:200-7.

19. Meniconi RL, Komatsu S, Perdigao F, Boëlle PY, Soubrane O, et al. Recurrent hepatocellular carcinoma: a Western strategy that emphasizes the impact of pathologic profile of the first resection. Surgery 2015;157:454-62.

20. Ercolani G, Grazi GL, Ravaioli M, Del Gaudio M, Gardini A, et al. Liver resection for hepatocellular carcinoma on cirrhosis: univariate and multivariate analysis of risk factors for intrahepatic recurrence. Ann Surg 2003;237:536-43.

21. Xing H, Zhang WG, Cescon M, Liang L, Li C, et al. Defining and predicting early recurrence after liver resection of hepatocellular carcinoma: a multi-institutional study. HPB (Oxford) 2019.

22. Joliat GR, Allemann P, Labgaa I, Demartines N, Halkic N. Treatment and outcomes of recurrent hepatocellular carcinomas. Langenbecks Arch Surg 2017;402:737-44.

23. Erridge S, Pucher PH, Markar SR, Malietzis G, Athanasiou T, et al. Meta-analysis of determinants of survival following treatment of recurrent hepatocellular carcinoma. Br J Surg 2017;104:1433-42.

24. Wu CC, Cheng SB, Yeh DC, Wang J, P'eng FK. Second and third hepatectomies for recurrent hepatocellular carcinoma are justified. Br J Surg 2009;96:1049-57.

25. Imamura H, Matsuyama Y, Tanaka E, Ohkubo T, Hasegawa K, et al. Risk factors contributing to early and late phase intrahepatic recurrence of hepatocellular carcinoma after hepatectomy. J Hepatol 2003;38:200-7.

26. Tabrizian P, Jibara G, Shrager B, Schwartz M, Roayaie S. Recurrence of hepatocellular cancer after resection: patterns, treatments, and prognosis. Ann Surg 2015;261:947-55.

27. Nagasue N, Yukaya H, Ogawa Y, Sasaki Y, Chang YC, et al. Second hepatic resection for recurrent hepatocellular carcinoma. Br J Surg 1986;73:434-8.

28. Hu RH, Lee PH, Yu SC, Dai HC, Sheu JC, et al. Surgical resection for recurrent hepatocellular carcinoma: prognosis and analysis of risk factors. Surgery 1996;120:23-9.

29. Lee PH, Lin WJ, Tsang YM, Hu RH, Sheu JC, et al. Clinical management of recurrent hepatocellular carcinoma. Ann Surg 1995;222:670-6.

30. Shimada M, Takenaka K, Taguchi K, Fujiwara Y, Gion T, et al. Prognostic factors after repeat hepatectomy for recurrent hepatocellular carcinoma. Ann Surg 1998;227:80-5.

31. Sun HC, Tang ZY, Ma ZC, Qin LX, Wang L, et al. The prognostic factor for outcome following second resection for intrahepatic recurrence of hepatocellular carcinoma with a hepatitis B virus infection background. J Cancer Res Clin Oncol 2005;131:284-8.

32. Huang ZY, Liang BY, Xiong M, Zhan DQ, Wei S, et al. Long-term outcomes of repeat hepatic resection in patients with recurrent hepatocellular carcinoma and analysis of recurrent types and their prognosis: a single-center experience in China. Ann Surg Oncol 
$2012 ; 19: 2515-25$

33. Minagawa M, Makuuchi M, Takayama T, Kokudo N. Selection criteria for repeat hepatectomy in patients with recurrent hepatocellular carcinoma. Ann Surg 2003;238:703-10.

34. Roayaie S, Bassi D, Tarchi P, Labow D, Schwartz M. Second hepatic resection for recurrent hepatocellular cancer: a Western experience. J Hepatol 2011;55:346-50.

35. Zou Q, Li J, Wu D, Yan Z, Wan X, et al. Nomograms for pre-operative and post-operative prediction of long-term survival of patients who underwent repeat hepatectomy for recurrent hepatocellular carcinoma. Ann Surg Oncol 2016;23:2618-26.

36. Chan DL, Morris DL, Chua TC. Clinical efficacy and predictors of outcomes of repeat hepatectomy for recurrent hepatocellular carcinoma - a systematic review. Surg Oncol 2013;22:e23-30.

37. Huang ZY, Liang BY, Xiong M, Zhan DQ, Wei S, et al. Long-term outcomes of repeat hepatic resection in patients with recurrent hepatocellular carcinoma and analysis of recurrent types and their prognosis: a single-center experience in China. Ann Surg Oncol 2012;19:2515-25.

38. Faber W, Seehofer D, Neuhaus P, Stockmann M, Denecke T, et al. Repeated liver resection for recurrent hepatocellular carcinoma. J Gastroenterol Hepatol 2011;26:1189-94.

39. Kubo S, Takemura S, Uenishi T, Yamamoto T, Ohba K, et al. Second hepatic resection for recurrent hepatocellular carcinoma in patients with chronic hepatitis C. World J Surg 2008;32:632-8.

40. Itamoto T, Nakahara H, Amano H, Kohashi T, Ohdan H, et al. Repeat hepatectomy for recurrent hepatocellular carcinoma. Surgery 2007;141:589-97.

41. Tralhão JG, Dagher I, Lino T, Roudié J, Franco D. Treatment of tumour recurrence after resection of hepatocellular carcinoma. Analysis of 97 consecutive patients. Eur J Surg Oncol 2007;33:746-51.

42. Kobayashi A, Kawasaki S, Miyagawa S, Miwa S, Noike T, et al. Results of 404 hepatic resections including 80 repeat hepatectomies for hepatocellular carcinoma. Hepatogastroenterology 2006;53:736-41.

43. Sugimachi K, Maehara S, Tanaka S, Shimada M, Sugimachi K. Repeat hepatectomy is the most useful treatment for recurrent hepatocellular carcinoma. J Hepatobiliary Pancreat Surg 2001;8:410-6.

44. Hu RH, Lee PH, Yu SC, Dai HC, Sheu JC, et al. Surgical resection for recurrent hepatocellular carcinoma: prognosis and analysis of risk factors. Surgery 1996;120:23-9.

45. Cai W, Liu Z, Xiao Y, Zhang W, Tang D, et al. Comparison of clinical outcomes of laparoscopic versus open surgery for recurrent hepatocellular carcinoma: a meta-analysis. Surg Endosc 2019;33:3550-7.

46. Halls MC, Berardi G, Cipriani F, Barkhatov L, Lainas P, et al. Development and validation of a difficulty score to predict intraoperative complications during laparoscopic liver resection. Br J Surg 2018;105:1182-91.

47. Majno PE, Sarasin FP, Mentha G, Hadengue A. Primary liver resection and salvage transplantation or primary liver transplantation in patients with single, small hepatocellular carcinoma and preserved liver function: an outcome-oriented decision analysis. Hepatology 2000;31:899-906.

48. Kostakis ID, Machairas N, Prodromidou A, Stamopoulos P, Garoufalia Z, et al. Comparison between salvage liver transplantation and repeat liver resection for recurrent hepatocellular carcinoma: a systematic review and meta-analysis. Transplant Proc 2019;51:433-6.

49. Lim C, Shinkawa H, Hasegawa K, Bhangui P, Salloum C, et al. Salvage liver transplantation or repeat hepatectomy for recurrent hepatocellular carcinoma: An intent-to-treat analysis. Liver Transpl 2017;23:1553-63.

50. Adam R, Azoulay D, Castaing D, Eshkenazy R, Pascal G, et al. Liver resection as a bridge to transplantation for hepatocellular carcinoma on cirrhosis: a reasonable strategy? Ann Surg 2003;238:508-18.

51. Wang HL, Mo DC, Zhong JH, Ma L, Wu FX, et al. Systematic review of treatment strategy for recurrent hepatocellular carcinoma: Salvage liver transplantation or curative locoregional therapy. Medicine (Baltimore) 2019;98:e14498.

52. Lucidi V, Gustot T, Moreno C, Donckier V. Liver transplantation in the context of organ shortage: toward extension and restriction of indications considering recent clinical data and ethical framework. Curr Opin Crit Care 2015;21:163-70.

53. Taura K, Ikai I, Hatano E, Fujii H, Uyama N, et al. Implication of frequent local ablation therapy for intrahepatic recurrence in prolonged survival of patients with hepatocellular carcinoma undergoing hepatic resection: an analysis of 610 patients over 16 years old. Ann Surg 2006;244:265-73.

54. Lü MD, Kuang M, Liang LJ, Xie XY, Peng BG, et al. Surgical resection versus percutaneous thermal ablation for early-stage hepatocellular carcinoma: a randomized clinical trial. Zhonghua Yi Xue Za Zhi 2006;86:801-5. (in Chinese)

55. Chen MS, Li JQ, Zheng Y, Guo RP, Liang HH, et al. A prospective randomized trial comparing percutaneous local ablative therapy and partial hepatectomy for small hepatocellular carcinoma. Ann Surg 2006;243:321-8.

56. Chan AC, Poon RT, Cheung TT, Chok KS, Chan SC, et al. Survival analysis of re-resection versus radiofrequency ablation for intrahepatic recurrence after hepatectomy for hepatocellular carcinoma. World J Surg 2012;36:151-6.

57. Gavriilidis P, Askari A, Azoulay D. Survival following redo hepatectomy vs radiofrequency ablation for recurrent hepatocellular carcinoma: a systematic review and meta-analysis. HPB (Oxford) 2017;19:3-9.

58. Thomasset SC, Dennison AR, Garcea G. Ablation for recurrent hepatocellular carcinoma: a systematic review of clinical efficacy and prognostic factors. World J Surg 2015;39:1150-60.

59. Wang K, Liu G, Li J, Yan Z, Xia Y, et al. Early intrahepatic recurrence of hepatocellular carcinoma after hepatectomy treated with rehepatectomy, ablation or chemoembolization: a prospective cohort study. Eur J Surg Oncol 2015;41:236-42.

60. Malagari K, Alexopoulou E, Chatzimichail K, Hall B, Koskinas J, et al. Transcatheter chemoembolization in the treatment of HCC in patients not eligible for curative treatments: midterm results of doxorubicin-loaded DC bead. Abdom Imaging 2008;33:512-9. 
61. Llovet JM, Real MI, Montaña X, Planas R, Coll S, et al.; Barcelona Liver Cancer Group. Arterial embolisation or chemoembolisation versus symptomatic treatment in patients with unresectable hepatocellular carcinoma: a randomised controlled trial. Lancet 2002;359:1734-9.

62. Jin YJ, Lee JW, Lee OH, Chung HJ, Kim YS, et al. Transarterial chemoembolization versus surgery/radiofrequency ablation for recurrent hepatocellular carcinoma with or without microvascular invasion. J Gastroenterol Hepatol 2014;29:1056-64.

63. Takayasu K, Arii S, Ikai I, Kudo M, Matsuyama Y, et al.; Liver Cancer Study Group of Japan. Overall survival after transarterial lipiodol infusion chemotherapy with or without embolization for unresectable hepatocellular carcinoma: propensity score analysis. AJR Am J Roentgenol 2010;194:830-7.

64. Erridge S, Pucher PH, Markar SR, Malietzis G, Athanasiou T, et al. Meta-analysis of determinants of survival following treatment of recurrent hepatocellular carcinoma. Br J Surg 2017;104:1433-42.

65. Llovet JM, Ricci S, Mazzaferro V, Hilgard P, Gane E, et al.; SHARP Investigators Study Group. Sorafenib in advanced hepatocellular carcinoma. N Engl J Med 2008;359:378-90.

66. Bruix J, Qin S, Merle P, Granito A, Huang YH, et al.; RESORCE Investigators. Regorafenib for patients with hepatocellular carcinoma who progressed on sorafenib treatment (RESORCE): a randomised, double-blind, placebo-controlled, phase 3 trial. Lancet 2017;389:56-66.

67. Kudo M, Finn RS, Qin S, Han KH, Ikeda K, et al. Lenvatinib versus sorafenib in first-line treatment of patients with unresectable hepatocellular carcinoma: a randomised phase 3 non-inferiority trial. Lancet 2018;391:1163-73.

68. Kumar M, Panda D. Role of supportive care for terminal stage hepatocellular carcinoma. J Clin Exp Hepatol 2014;4:S130-9. 